\title{
Influences of Fine-Particle Bombarding and Conventional Shot Peening on Surface Properties of Steel
}

\author{
Tatsuro Morita ${ }^{1, *}$, Sho Noda ${ }^{2}$ and Chuji Kagaya ${ }^{3}$ \\ ${ }^{1}$ Department of Mechanical and System Engineering, Graduate School of Science and Technology, \\ Kyoto Institute of Technology, Kyoto 606-8585, Japan \\ ${ }^{2}$ Tokyo Office, Mitsubishi Electric Building Techno-Service Co., Ltd., Tokyo 116-0002, Japan \\ ${ }^{3}$ Department of Mechanical Engineering, Faculty of Engineering, Chubu University, Kasugai 487-8501, Japan
}

\begin{abstract}
This study was conducted to investigate the influences of fine-particle bombarding (FPB, maximum diameter of collision particles: $34 \mu \mathrm{m}$ ) and conventional shot peening $(510 \mu \mathrm{m})$ on the surface properties of steel. The influence of injection pressure in FPB was also examined. The microstructures near surfaces were nano-crystallized by FPB and shot peening. Grain size of nano-crystals was more markedly decreased by FPB than shot peening, and further reduced by the use of high injection pressure in FPB. Surface hardness increased as the grain size of nano-crystals decreased. The hardened layers of the FPBed materials became thicker by the use of high injection pressure; however, they were still shallower than the hardened layers of the shot-peened materials. Compressive residual stress measured on surfaces was higher in FPBed materials than in shot-peened materials. The use of high injection pressure in FPB was not effective to further increase this stress. [doi:10.2320/matertrans.M2013322]
\end{abstract}

(Received August 23, 2013; Accepted January 9, 2014; Published February 21, 2014)

Keywords: fine-particle bombarding, shot peening, injection pressure, hardness of substrates, mild steel, microstructure, nano-crystals, surface hardness, hardness distribution, residual stress

\section{Introduction}

Fine-particle bombarding (FPB) is a surface modification method in which fine particles bombard the surface of metals. ${ }^{1)}$ In recent years, this method has been widely used for various engineering applications because of its marked effects. In its fundamental principle, FPB is similar to conventional shot peening. The difference between them is in the size of collision particles: namely, the particle size of FPB (maximum diameter $\leqq 200 \mu \mathrm{m}$ ) is much smaller than that of shot peening (usually $\geqq 500 \mu \mathrm{m}$ ).

Particle size controls the depth of plastic deformation and applied energy density per unit volume. ${ }^{2}$ In the case of FPB, since the kinetic energy of one particle is low, the plasticdeformed region is very shallow; however, numerous fine particles repeatedly collide at the same positions. As a result, applied energy density becomes markedly higher in FPB than in shot peening. Marked effects of FPB result from the above high energy density.

Wear resistance and fatigue strength of metals are closely related with surface properties, such as the surface hardness, residual stress and surface roughness. FPB significantly increases the surface hardness through nano-crystallization of the microstructure, ${ }^{3-6)}$ and introduces high compressive residual stress ${ }^{2)}$ without marked deterioration of surface roughness. Therefore, FPB greatly improves wear resistance ${ }^{7)}$ and fatigue strength. ${ }^{2,8-10)}$

According to our studies, the combination of plasma treatments with FPB is more effective to improve the fatigue strength of titanium than single treatments. ${ }^{1-15)}$ FPB can provide desirable functionality, such as high corrosion resistance by surface alloying. ${ }^{16,17)}$

Although many results concerning FPB have been accumulated as mentioned above, more fundamental data

*Corresponding author, E-mail: morita@kit.ac.jp are required for progression. Our previous study examined the influence of substrate hardness on the properties of the surface layers formed by FPB. ${ }^{18)}$ This study was conducted further to investigate the influences of FPB and conventional shot peening on surface properties of steel. The influence of injection pressure in FPB was also examined.

As substrates, two materials with different hardness were prepared from mild steel. The surface properties of the FPBed and shot-peened materials, such as microstructures, surface hardness, hardness distribution and residual stress, were systematically examined. In particular, surface microstructures were observed by transmission electron microscopy (TEM) in detail. Plastic deformation near surfaces was investigated on cross sections by electron backscatter diffraction (EBSD) analysis.

\section{Materials and Experimental Procedures}

Table 1 shows the chemical composition of mild steel JIS S45C used in this study. The material was the same as that used in the previous study. ${ }^{18)}$ It was supplied as round bars with a diameter of $12 \mathrm{~mm}$.

The material was machined to button-shaped specimens (diameter: $12 \mathrm{~mm}$, thickness: $10 \mathrm{~mm}$ ) and fully annealed to eliminate the process history. The specimens were quenched and tempered at $473 \mathrm{~K}$ and $873 \mathrm{~K}$ to change hardness (Table 2). The test sections of specimens were polished with emery papers and alumina powders to mirror surfaces. Hereafter, these substrates are called "T473 material" and "T873 material", respectively.

Table 1 Chemical composition of mild steel JIS S45C used in this study (mass\%).

\begin{tabular}{cccccccc}
\hline $\mathrm{C}$ & $\mathrm{Si}$ & $\mathrm{Mn}$ & $\mathrm{P}$ & $\mathrm{S}$ & $\mathrm{Cu}$ & $\mathrm{Ni}$ & $\mathrm{Cr}$ \\
\hline 0.44 & 0.20 & 0.70 & 0.022 & 0.014 & 0.11 & 0.072 & 0.166 \\
\hline
\end{tabular}


Table 2 Conditions of the heat treatments, FPB and shot peening.

\begin{tabular}{|c|c|c|c|c|c|c|c|}
\hline & \multirow[b]{2}{*}{ Annealing } & \multirow[b]{2}{*}{ Quenching } & \multirow[b]{2}{*}{ Tempering } & \multicolumn{4}{|c|}{ FPB and shot peening } \\
\hline & & & & $\begin{array}{c}\text { Maximum diameter } \\
\text { of particles, } \\
d / \mu \mathrm{m}\end{array}$ & $\begin{array}{c}\text { Injection pressure, } \\
p / \mathrm{MPa}\end{array}$ & $\begin{array}{c}\text { Material of } \\
\text { particles }\end{array}$ & $\begin{array}{c}\text { Treatment time, } \\
t / \mathrm{s}\end{array}$ \\
\hline T473/FPB-H & \multirow{6}{*}{$\begin{array}{c}1083 \mathrm{~K}, \\
3.6 \mathrm{ks}, \\
\text { F.C. }\end{array}$} & \multirow{6}{*}{$\begin{array}{c}1118 \mathrm{~K}, \\
300 \mathrm{~s}, \\
\mathrm{Q} .\end{array}$} & $473 \mathrm{~K}$ & $34(\# 400)$ & 0.75 & \multirow{6}{*}{$\begin{array}{l}\text { High-speed steel } \\
\text { (about } 1000 \mathrm{Hv} \text { ) }\end{array}$} & \multirow{6}{*}{10} \\
\hline $\mathrm{T} 473 / \mathrm{FPB}^{*}$ & & & $3.6 \mathrm{ks}$ & $34(\# 400)$ & 0.5 & & \\
\hline T473/SP & & & A.C. & $510(\# 30)$ & 0.5 & & \\
\hline T873/FPB-H & & & $873 \mathrm{~K}$ & $34(\# 400)$ & 0.75 & & \\
\hline T873/FPB* & & & $3.6 \mathrm{ks}$ & $34(\# 400)$ & 0.5 & & \\
\hline T873/SP & & & A.C. & $510(\# 30)$ & 0.5 & & \\
\hline
\end{tabular}

F.C.: furnace-cooled, Q.: quenched, A.C.: air-cooled, ${ }^{*}$ Previous study. ${ }^{18)}$

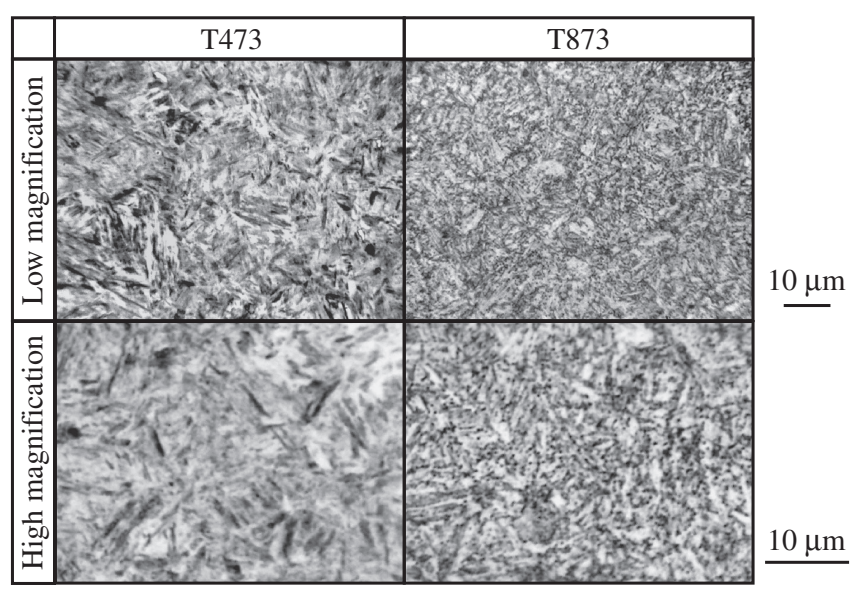

Fig. 1 Microstructures of the substrates.

Table 3 Mechanical properties and hardness of the substrates.

\begin{tabular}{ccccccc}
\hline & $\begin{array}{c}\text { Young's } \\
\text { modulus, } \\
E / \mathrm{GPa}\end{array}$ & $\begin{array}{c}\text { Yield } \\
\text { strength, } \\
\sigma_{\mathrm{Y}} / \mathrm{MPa}\end{array}$ & $\begin{array}{c}\text { Tensile } \\
\text { strength, } \\
\sigma_{\mathrm{TS}} / \mathrm{MPa}\end{array}$ & $\begin{array}{c}\text { Elongation } \\
(\%)\end{array}$ & $\begin{array}{c}\text { Reduction } \\
\text { in area } \\
(\%)\end{array}$ & $\begin{array}{c}\text { Hardness } \\
H_{\mathrm{I}} / \mathrm{Hv}\end{array}$ \\
\hline $\mathrm{T} 473$ & 209 & 1707 & 2025 & 12.0 & 33.6 & 606 \\
$\mathrm{~T} 873$ & 210 & 746 & 832 & 18.7 & 60.1 & 296 \\
\hline
\end{tabular}

For reference, their microstructures, mechanical properties and hardness are shown in Fig. 1 and Table 3. The microstructures of the T473 and T873 materials were different concerning precipitated carbides ( $\varepsilon$-carbide and spherical carbide) because the tempering temperature was different.

In this study, FPB and shot peening were conducted under the conditions labeled "FPB-H" and "SP" in Table 2, which mean FPB under high injection pressure $(0.75 \mathrm{MPa})$ and shot-peening, respectively. In Table 2 , the condition of FPB examined in the previous study was labeled "FPB". The results of the previous study were used for direct comparison with the results obtained in this study.

Surface features of the treated surfaces were observed. Microstructures near surfaces were observed on cross sections polished to mirror surfaces and etched by $1 \%$ Nital etchant (mixture of nitric acid and ethanol). These observations were performed by scanning electron microscopy (SEM).

To investigate the surface microstructures in detail, TEM observation and electron diffraction were conducted in the direction normal to the treated surfaces. Samples with a diameter of $3 \mathrm{~mm}$ were cut from the treated surfaces. To avoid damage, the samples were carefully polished from the substrate side, and then ion-milled. Grain size of the surface microstructures was obtained from the results of TEM observation.

Surface hardness was measured by a micro-Vickers hardness tester under test force of $490 \mathrm{mN}$ (50 gf) and dwell time of $15 \mathrm{~s}$. Five appropriate square indentations were selected and the mean values of hardness were used as data. Hardness distributions were obtained on polished cross sections under the test condition mentioned above. In this test, hardness was measured at each depth five times and the averages were used as data.

Plastic deformation near surfaces was examined on cross sections by EBSD analysis. As data, inverse pole figure (IPF) maps were obtained under the minimum confidence index (CI) of 0.1 .

$\mathrm{X}$-ray residual stress measurement was performed on the treated surfaces. The measurement conditions were as follows: X-ray: $\mathrm{Cr} \mathrm{K} \alpha$, diffraction plane: (211), diffraction angle: $2 \theta=156.4 \mathrm{deg} ., \psi$ angles: $\psi=10,20,30,35,40 \mathrm{deg}$. ( $\sin ^{2} \psi$ method), oscillation: $+/-3$ deg., peak search: fullwidth at half-maximum method, stress constant: $K=$ $-317.9 \mathrm{MPa} / \mathrm{deg}$.

\section{Results and Discussion}

\subsection{Surface features and microstructures}

Figure 2 shows the surface features of the FPBed and shotpeened materials. This figure includes the microstructures observed on cross sections.

As shown in Fig. 2, craters were formed on the surfaces by the collision of particles. The size of craters was increased by the use of high injection pressure in FPB (T473/FPB-H, T873/FPB-H). It was still smaller than that by shot peening (T473/SP, T873/SP). If compared under the same treatment conditions, craters became larger by decreasing the hardness of the substrates.

Distinguishable surface layers, shown by dotted lines in Fig. 2, were observed on the cross sections of the FPBed materials (T473/FPB-H, T473/FPB, T873/FPB-H, and T873/FPB). As explained in section 3.3, the microstructures of the surface layers were nano-crystallized. Some studies have reported that such distinguishable surface layers were 

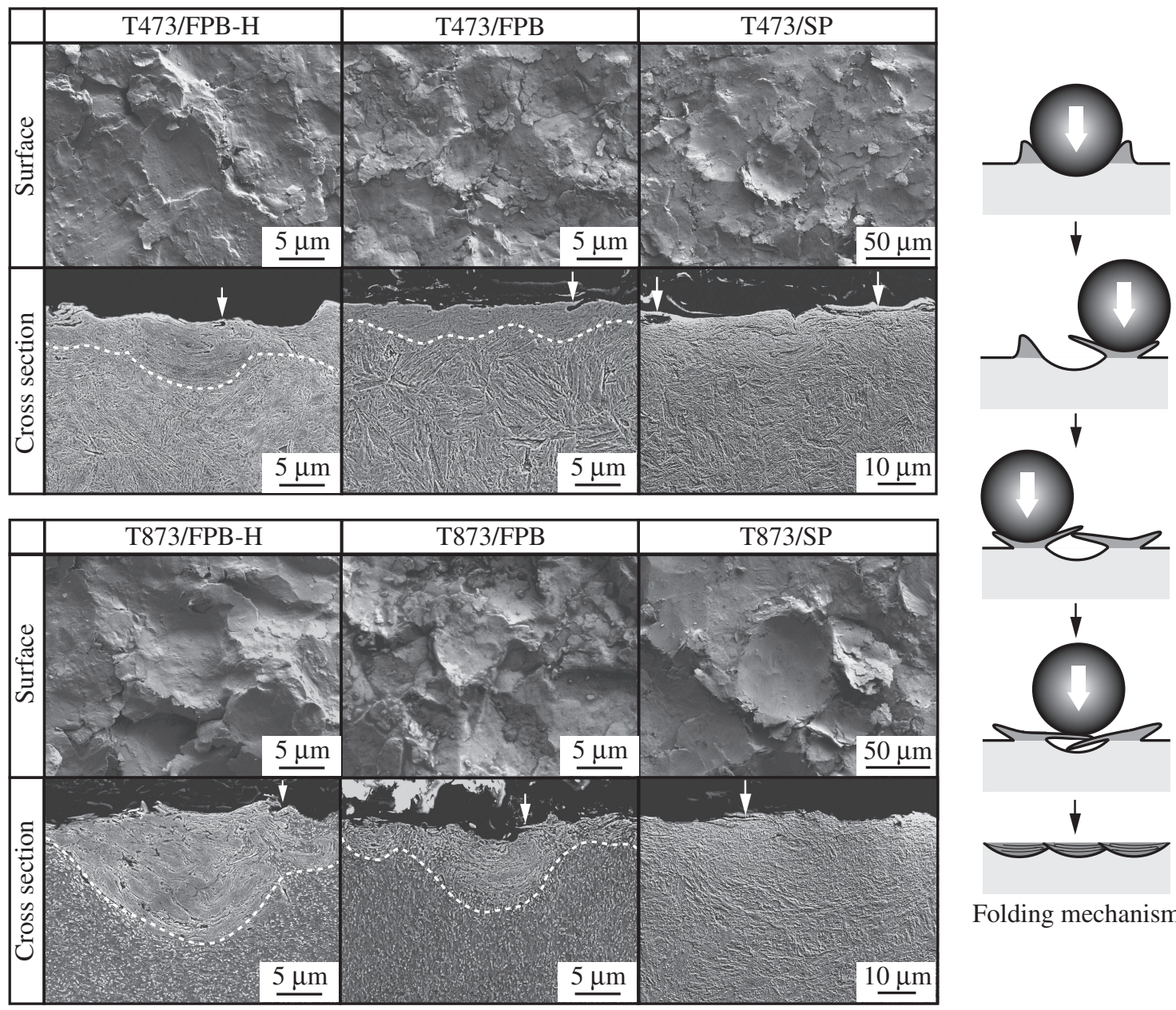

Folding mechanism

Fig. 2 Surface features and the microstructures observed on cross sections.

generated by FPB. ${ }^{3-6)}$ According to our previous study ${ }^{18)}$ and another paper, ${ }^{19)}$ projections formed around craters were repeatedly folded by the collision of particles and surface layers were generated. In this study, the above mechanism is called the "folding mechanism".

Since the use of high injection pressure in FPB increased the kinetic energy of collision particles, plastic deformation reached deeper positions. Accordingly, the surface layers of the T473/FPB-H and T873/FPB-H materials were thicker than those of the T473/FPB and T873/FPB materials. The decrease in the hardness of the substrates increased the depth of plastic deformation, so the surface layers of the T873/ FPB-H and T873/FPB materials were thicker than those of the T473/FPB-H and T473/FPB materials.

In the shot-peened materials (T473/SP, T873/SP), the activation of the folding mechanism was confirmed near the surface (arrow) as well as in the FPBed materials. The microstructures near the surfaces were nano-crystallized by shot peening as explained in section 3.3; however, the surface layers could not be distinguished in the shot-peened materials through contrast by etching because the microstructures gradually changed from the surfaces to the inside.

\subsection{Relationship between hardness of substrates and surface hardness}

Figure 3 shows the relationship between the hardness of the substrates and the surface hardness of the FPBed and

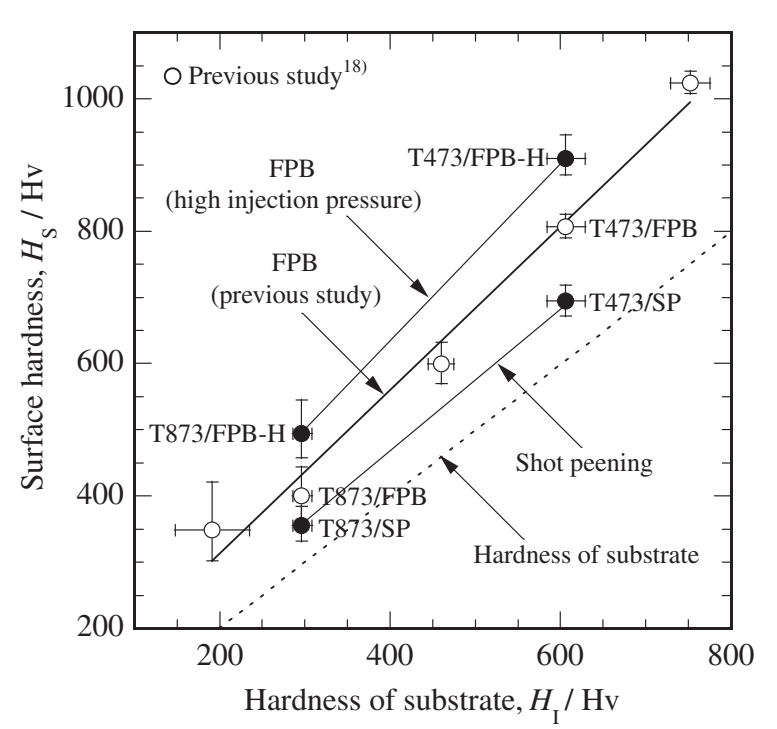

Fig. 3 Relationship between the hardness of the substrates and surface hardness.

shot-peened materials. In the figure, the results obtained in this study are shown by solid circles and those obtained in the previous study are shown by open circles.

The surface hardness of the materials FPBed under the same condition (open circle, Fig. 3) increased with the 


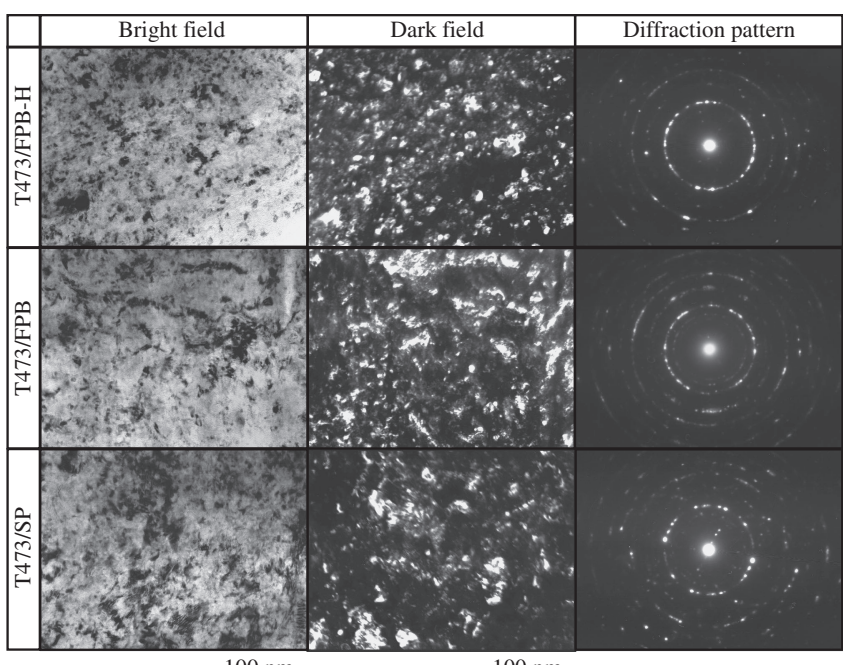

$100 \mathrm{~nm}$

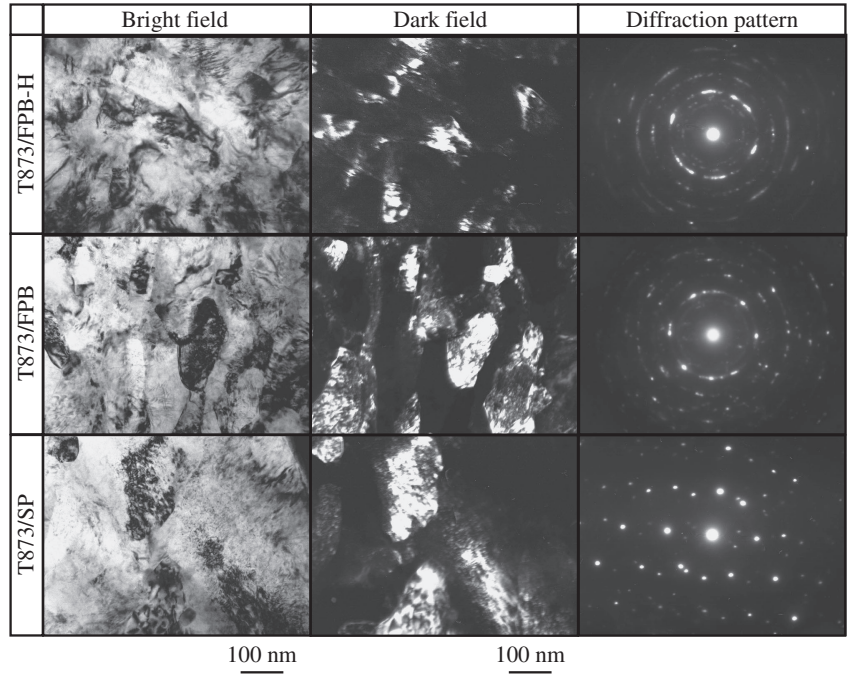

Fig. 4 Surface microstructures observed by TEM and the diffraction patterns.

increase in the hardness of the substrates. If the hardness of the substrates was the same, surface hardness was increased by the use of high injection pressure in FPB, as understood by comparing T473/FPB-H and T473/FPB materials or T873/FPB-H and T873/FPB materials. The surface hardness of FPBed materials was higher than that of shot-peened materials, as understood by comparing T473/FPB and T473/ SP materials or T873/FPB and T873/SP materials.

\subsection{Relationship between surface microstructures and surface hardness}

Figure 4 shows the surface microstructures observed in bright and dark fields by TEM, together with the diffraction patterns obtained in the observed regions. In Fig. 5, the results of Fig. 3 have been rearranged to show the relationship between the grain size of the surface microstructures and surface hardness.

It is well known that dynamic recrystallization occurs in the hot working of metals. The recrystallized grain size depends on temperature and strain rate, so-called ZenerHollomon parameters, but does not depend on the strain. On the other hand, when metals are cold-worked under conditions of severe plastic deformation, a different type of

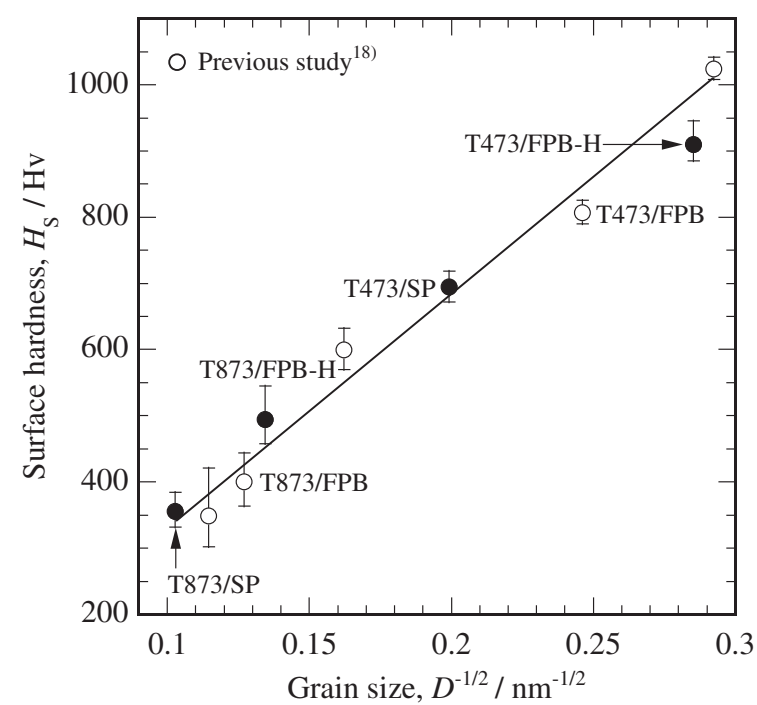

Fig. 5 Relationship between the grain size of the surface microstructures and surface hardness.

dynamic recrystallization is induced. ${ }^{20)}$ This is often called "continuous dynamic recrystallization". In this type of dynamic recrystallization, grain size depends on the severity of plastic deformation.

Since FPB induces nano-crystallization of the surface microstructures through continuous dynamic recrystallization, ${ }^{3-6)}$ it is expected that the grain size of nano-crystals depends on the degree of plastic deformation. Plastic deformation near the surface becomes severer by the decrease of collision particle size and increase in injection pressure. In the case of substrates with high hardness, since smaller projections are made around craters and folded repeatedly, severe plastic deformation is induced near the surface. ${ }^{18)}$ Accordingly, plastic deformation near the surface becomes severer also by the increase in the hardness of the substrates.

The obtained results supported the above expectation, as mentioned below. As seen in Fig. 4, the surface microstructures were nano-crystallized in all materials, including the shot-peened materials (T473/SP, T873/SP) in which no surface layer was observed. The grain size of nano-crystals was more markedly decreased by FPB than by shot peening, and further reduced by the use of high injection pressure in FPB. If compared under the same treatment conditions, the grain size of nano-crystals was decreased with the increase in the hardness of the substrates.

Some studies concerning nano-crystalline materials have reported that hardness continued to increase with decreasing grain size even in the region of very small grains of less than $100 \mathrm{~nm}^{21-24)}$ Corresponding to these studies, the surface hardness was increased with the reduction in the grain size of the surface microstructures, and there was a Hall-Petch relationship between them, as shown in Fig. 5.

Although dislocation hardening affects the surface hardness, it is difficult to distinguish the influence of dislocation hardening from that of grain refinement; however, Kimura reported that the hardness of severely plastic-deformed metal was controlled by grain refinement rather than dislocation hardening when the hardness was beyond about $500 \mathrm{Hv}^{22}$ ) 
In this study, since the hardness of the substrates was changed by tempering, the characteristics of cementite particles can affect the microstructures of the surface layers. $\mathrm{Xu}$ has reported that carbides in steel were dissolved by severe plastic deformation. ${ }^{25)}$ No cementite particles were observed in the surface layers by TEM observation. Accordingly, it was thought that cementite particles were dissolved by FPB and shot peening and had no influence.

Other factors such as Coble creep and the distribution of grain size can affect the hardness of nano-crystalline materials. Coble creep is mass flow due to grain boundary diffusion. Some previous studies reported that Coble creep decreases the hardness of nano-crystalline materials at a grain size $\leqq 10-30 \mathrm{~nm}$, even at room temperature. ${ }^{23,24)}$ The distribution of grain size also affects the hardness of nanocrystalline materials as well as the average grain size. ${ }^{26)}$

Nevertheless, the results obtained in this study (Fig. 5) showed that surface hardness increased with the decreasing grain size of nano-crystals. In consequence, it is probable that grain refinement is the factor most strongly controlling the surface hardness of FPBed and shot-peened materials.

\subsection{IPF maps and hardness distributions}

Figure 6 shows the IPF maps obtained on cross sections of FPBed and shot-peened materials. In this figure, the dotted lines show the outlines of the surfaces. Figure 7 shows their hardness distributions measured on cross sections together with surface hardness.

Firstly, the relationship between the microstructures and the hardness distribution is explained based on the results concerning the group of T873 materials (T873/FPB-H, T873/FPB, and T873/SP). In T873/FPB material (Fig. 6), the IPF map of the surface layer was imperfect because the grain size of the microstructure was very small. The results explained in the previous sections suggested that the microstructure of the surface layer was almost uniformly nano-crystallized (Figs. 2, 4). Because of the above uniform microstructure, the hardness distribution of $\mathrm{T} 873 / \mathrm{FPB}$ material was constant near the surface (solid circle in Fig. 7).

In the region beneath the surface layer of T873/FPB material, the microstructure was compressed and refined, so hardness was increased. Since this region was thin, the hardness distribution sharply dropped from the surface hardness level to the hardness of the substrate in the depth direction.

In T873/FPB-H material, the grain size of the microstructure of the surface layer was further decreased by the use of high injection pressure in FPB and the thickness of the layer was increased, as explained in the previous sections. In the region beneath the surface layer, the compressed and refined microstructure extended to a deeper position (Fig. 6). As a result, hardness near the surface (solid triangle in Fig. 7) was higher than that of the T873/FPB material, and the hardened layer became thicker.

The microstructure and hardness distribution of the shotpeened material (T873/SP) were markedly different from FPBed materials. As shown in Fig. 6, the microstructure near the surface was nano-crystallized; however, its grain size was larger than in FPBed materials. The refined microstructure greatly extended to a much deeper position, and its grain size

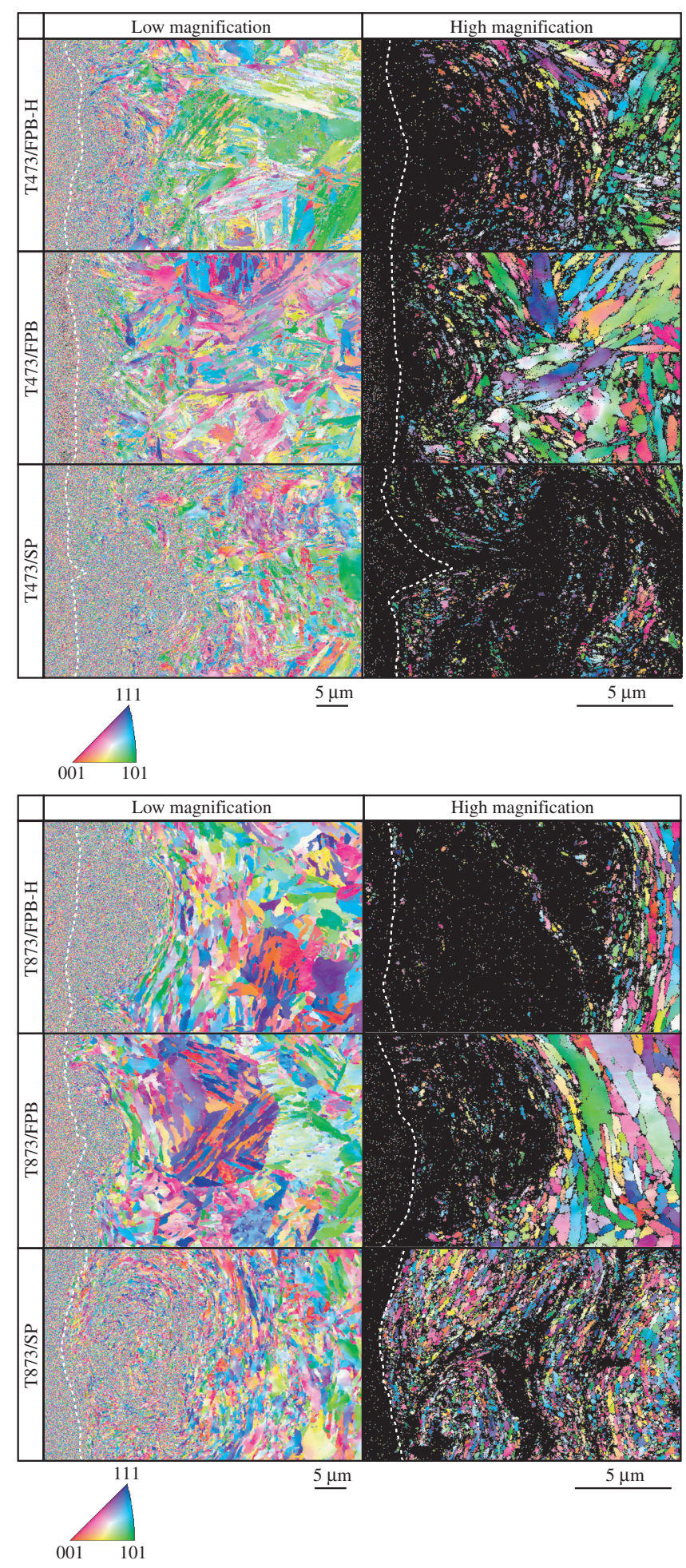

Fig. 6 IPF maps obtained near the surfaces on cross sections.

gradually increased in the depth direction. The above change in the microstructure was reflected in the hardness distribution (solid square in Fig. 7); that is, while the hardness near the surface was lower than in FPBed materials, the hardened region reached a much deeper position.

In the group of T473 materials, since the hardness of the substrates was higher than in the group of T873 materials described above, the affected regions were thinner (Fig. 6) and the hardness distributions were located at higher positions (open circle in Fig. 7); however, the tendencies of 


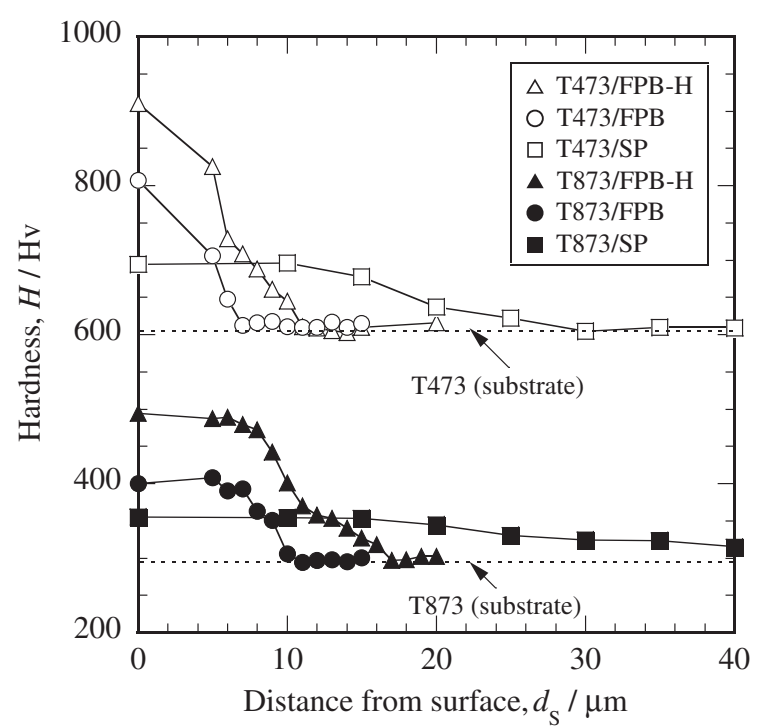

Fig. 7 Hardness distributions from the surfaces to the inside.

the changes in the microstructures and hardness distributions were almost the same as in the group of T873 materials.

Dislocation hardening also affects hardness distribution. Its contribution could not be distinguished from refinement of the microstructures in the range of this study, because both depend on the degree of plastic deformation induced near the surface.

\subsection{Residual stress}

Figure 8 shows the relationship between the hardness of the substrates and residual stress measured on the treated surfaces. The figure includes the results of the materials examined in this study (solid circle) and the results obtained in the previous study (open circle).

When particles collide with a metal surface, the plasticdeformed surface region tends to expand, but is effectively constrained by the material volume below it. As a result, compressive residual stress is introduced near the surface. According to this generation mechanism, the absolute value of compressive residual stress depends on both the degree of plastic deformation induced near the surface and the hardness of substrates.

When the hardness of the substrates increased, plastic deformation was markedly concentrated in the vicinity of the surface. At the same time, expansion of the plastic-deformed surface regions was strongly restricted by the substrates possessing higher hardness. Accordingly, if compared under the same treatment conditions, the absolute value of compressive residual stress increased by increasing the hardness of the substrates, as shown in Fig. 8.

The use of high injection pressure in FPB increased the degree of plastic deformation induced near the surface, as mentioned in previous sections. Although the absolute value of compressive residual stress of T873/FPB-H material was higher than T873/FPB material (Fig. 8), the value of T473/FPB-H material was slightly lower than T473/FPB material. In the range of the obtained results, the use of high injection pressure in FPB was not very effective to increase compressive residual stress. As the cause, it was thought that the surface layers became thicker by the use of high injection

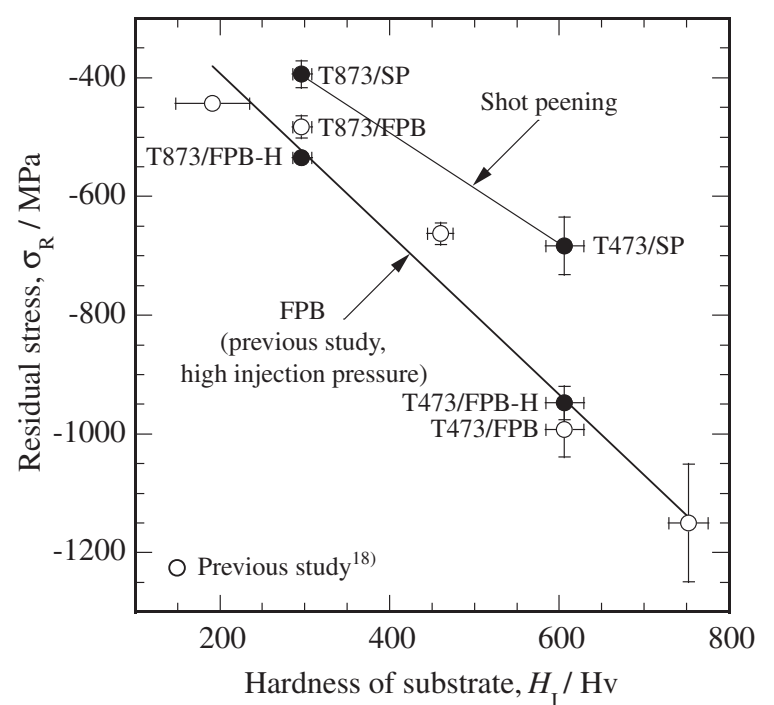

Fig. 8 Relationship between the hardness of the substrates and residual stress measured on the treated surfaces.

pressure, so that the deformation in the layers was not sufficiently restricted by the substrates.

The region to which plastic deformation reached was much thicker in shot peening than in FPB because of the difference in the kinetic energy of particles. Accordingly, the plasticdeformed surface regions of shot-peened materials were difficult to restrict by the substrates. As a result, the absolute values of compressive residual stress were much lower in shot-peened materials (T473/SP, T873/SP) than FPBed materials (T473/FPB, T873/FPB).

\section{Conclusions}

The obtained results are summarized as follows. For reference, an illustration is shown in Fig. 9.

(1) The microstructures near the surfaces were nanocrystallized by FPB and shot peening. Relating to the degree of plastic deformation induced near the surface, the grain size of the surface microstructures was more markedly decreased by FPB than shot peening, and further reduced by the use of high injection pressure in FPB.

(2) Surface hardness was closely connected with the grain size of the surface microstructures, and it increased as the grain size decreased.

(3) The use of high injection pressure in FPB increased the surface hardness and thickness of the hardened layers; however, it was not very effective for increasing compressive residual stress.

(4) The hardened layers of shot-peened materials were markedly thicker than those of FPBed materials. Their surface hardness and the absolute value of compressive residual stress were much lower than those of FPBed materials.

(5) If compared under the same treatment conditions, the increase in the hardness of the substrates resulted in fine surface microstructures, higher surface hardness, thinner hardened layers, and higher compressive residual stress. 

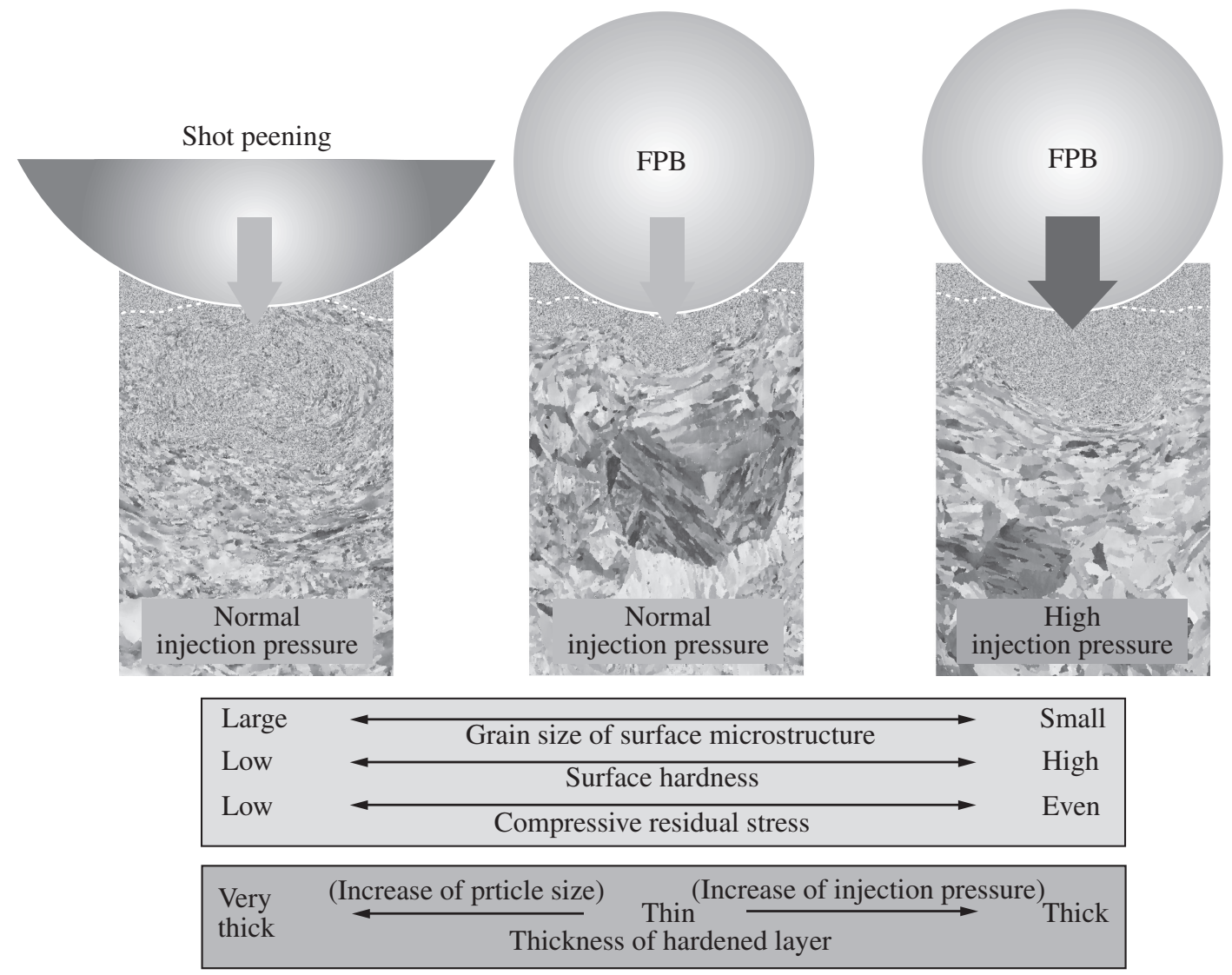

Fig. 9 Schematic illustration to explain the influence of the treatment conditions on surface properties.

\section{Acknowledgments}

This research was partially supported by the Japan Society for the Promotion of Science, Grant-in-Aid for Scientific Research (C), 2012-2014, No. 24560098. The authors gratefully acknowledge the support. The authors sincerely thank Fujikihan Co., Ltd. for FPB and shot peening.

\section{REFERENCES}

1) Fujikihan, Co., Ltd.: Japanese Patent No. 1594395.

2) T. Morita, H. Nakaguchi, S. Noda and C. Kagaya: Mater. Trans. 53 (2012) 1938-1945.

3) M. Umemoto, Y. Todaka and K. Tsuchiya: Mater. Trans. 44 (2003) 1488-1493.

4) M. Umemoto: Mater. Trans. 44 (2003) 1900-1911.

5) Y. Todaka, M. Umemoto, Y. Watanabe, A. Yamazaki, C. Wang and K. Tsuchiya: ISIJ Int. 47 (2007) 157-162.

6) J. L. Liu, M. Umemoto, Y. Todaka and K. Tsuchiya: J. Mater. Sci. 42 (2007) 7716-7720.

7) X. Y. Wang and D. Y. Li: Wear 255 (2003) 836-845.

8) M. Benedetti, T. Bortolamedi and V. Fontanari: Int. J. Fatigue 26 (2004) 889-897.

9) M. Nakajima, M. Kamiya, H. Itoga, K. Tokaji and H. Ko: Int. J. Fatigue 28 (2006) 1540-1546.

10) T. Morita, T. Sakata, C. Kagaya and K. Kawasaki: J. Japan Inst. Metals 75 (2011) 532-538.

11) T. Morita, T. Ohtomo, C. Kagaya, S. Tanaka and N. Tsuji: J. Soc. Mater. Sci. Japan 56 (2007) 872-879.
12) T. Morita, T. Ohtomo, C. Kagaya, N. Tsuji, S. Tanaka and T. Miyasaka: Ti-2007 Science and Technology II, (The Japan Institute of Metals and Materials, 2007) pp. 1659-1662.

13) N. Tsuji, S. Tanaka and T. Takasugi: Mater. Sci. Eng. A 499 (2009) $482-488$.

14) T. Morita, N. Uehigashi and C. Kagaya: Mater. Trans. 54 (2013) 2227.

15) T. Morita, N. Uehigashi and C. Kagaya: Mater. Trans. 54 (2013) 17191724 .

16) T. Morita, T. Yorino, C. Kagaya and Y. Miyasaka: Trans. Jpn. Soc. Mech. Eng. A 77 (2011) 1331-1339.

17) T. Morita, A. Sakamoto, C. Kagaya and H. Nakaguchi: Proc. 10th Int. Con. on Shot Peening ICSP10, (2008) pp. 211-216.

18) T. Morita, S. Noda and C. Kagaya: Mater. Sci. Eng. A 574 (2013) 197204.

19) S. Takaki, M. Kumagai, Y. Ito, S. Konuma and E. Shimodaira: Testuto-Hagane 92 (2006) 318-326.

20) X. Zhang, H. Wang, J. Narayan and C. C. Koch: Acta Mater. 49 (2001) 1319-1326.

21) P. G. Sanders, C. J. Youngdahl and J. R. Weertman: Mater. Sci. Eng. A 234-236 (1997) 77-82.

22) Y. Kimura, H. Hidaka and S. Takaki: Mater. Trans. 40 (1999) 14911157.

23) R. A. Masumura, P. M. Hazzledine and C. S. Pande: Acta Mater. 46 (1998) 4527-4534.

24) H. Hidaka, T. Tsuchiya and S. Takaki: Scr. Mater. 44 (2001) 15031506.

25) Y. Xu, Z. G. Liu, M. Umemoto and T. Tsuchiya: Metall. Mater. Trans. A 33 (2002) 2195-2203.

26) T. Morita, R. Mitra and J. R. Weertman: Mater. Trans. 45 (2004) 502508. 